\title{
Hematopoietic Cell Donor Eligibility
}

National Cancer Institute

\section{Source}

National Cancer Institute. Hematopoietic Cell Donor Eligibility. NCI Thesaurus. Code C159528.

Determination that potential hematopoietic cell donor does or does not possess risk factors for relevant communicable diseases (as defined by the FDA) and identified through screening, testing, physical evidence, and review of readily available relevant medical records. 